\title{
Editorial: Cyberpsychology has readers from 192 countries
}

\author{
David Smahel ${ }^{1}$, Lenka Dedkova ${ }^{1}$, \& Kristian Daneback ${ }^{2}$ \\ ${ }^{1}$ Faculty of Social Studies, Masaryk University, Brno, Czech Republic \\ ${ }^{2}$ Department of Social Work, University of Gothenburg, Gothenburg, Sweden
}

Dear researchers, colleagues, and readers interested in internet-related research,

We are honored to present the fourth issue of the 11th volume of Cyberpsychology: Journal of Psychosocial Research on Cyberspace. In this editorial, we will summarize the very successful year 2017. First, we will describe news from internationally important databases that cover our journal - the Web of Science and Scopus. Then we will focus on the visitors of Cyberpsychology and their country of residence. We will also present some journal statistics for 2017 - the number of submissions, the number of accepted articles, the number of rejections, and the time for internal decisions. Last, but not least, we will introduce the five articles which are included in this issue.

\section{Cyberpsychology in the Web of Science and Scopus}

From the perspective of coverage in databases, Cyberpsychology had a very successful year. First, we got unofficial news from a Thomson Reuters editor that the journal will be included in the Social Sciences Citation Index (SSCI) and the Current Contents/Social and Behavioral Sciences (CC/S\&BS) of the Web of Science in 2018, which means that we will receive the impact factor. This is great news because it shows that Cyberpsychology is recognized as a high quality journal within the academic community. But, this also brings more responsibility. We can expect more readers as well as more manuscript submissions for the editorial team to manage. We are already preparing for the influx by implementing a new submission system, which should be put in place in the first half of 2018.

The increasing impact of Cyberpsychology is also evident from the indexes of the Scopus database. The figure below displays the increasing values of the main SJR index (which is "a size-independent prestige indicator that ranks journals by their 'average prestige per article'"), the increasing total cites, and the citations per document. The value of the index "Cites per document per 2 years" is counted in the same way as the impact factor from the Web of Science. Cyberpsychology is getting better in all indexes and we are currently a $2 \mathrm{Q}$ (second quartile) journal in the "Psychology (miscellaneous)" area. See all statistics in Scopus here.

\section{Visitors of Cyberpsychology. People from the Entire World}

The past year of the journal was successful not only because of its increasing scientific impact but also because of the improvement to the technical process which enables us to run the journal. We moved the journal to a more robust solution, the Open Journal System, which is administered by Masaryk University. Thanks to this change we are also able to better analyze the readership of Cyberpsychology, as we show below. The next analyses show the six-month time frame from the beginning of June (when we made the switch to the new platform) to the end of November. 


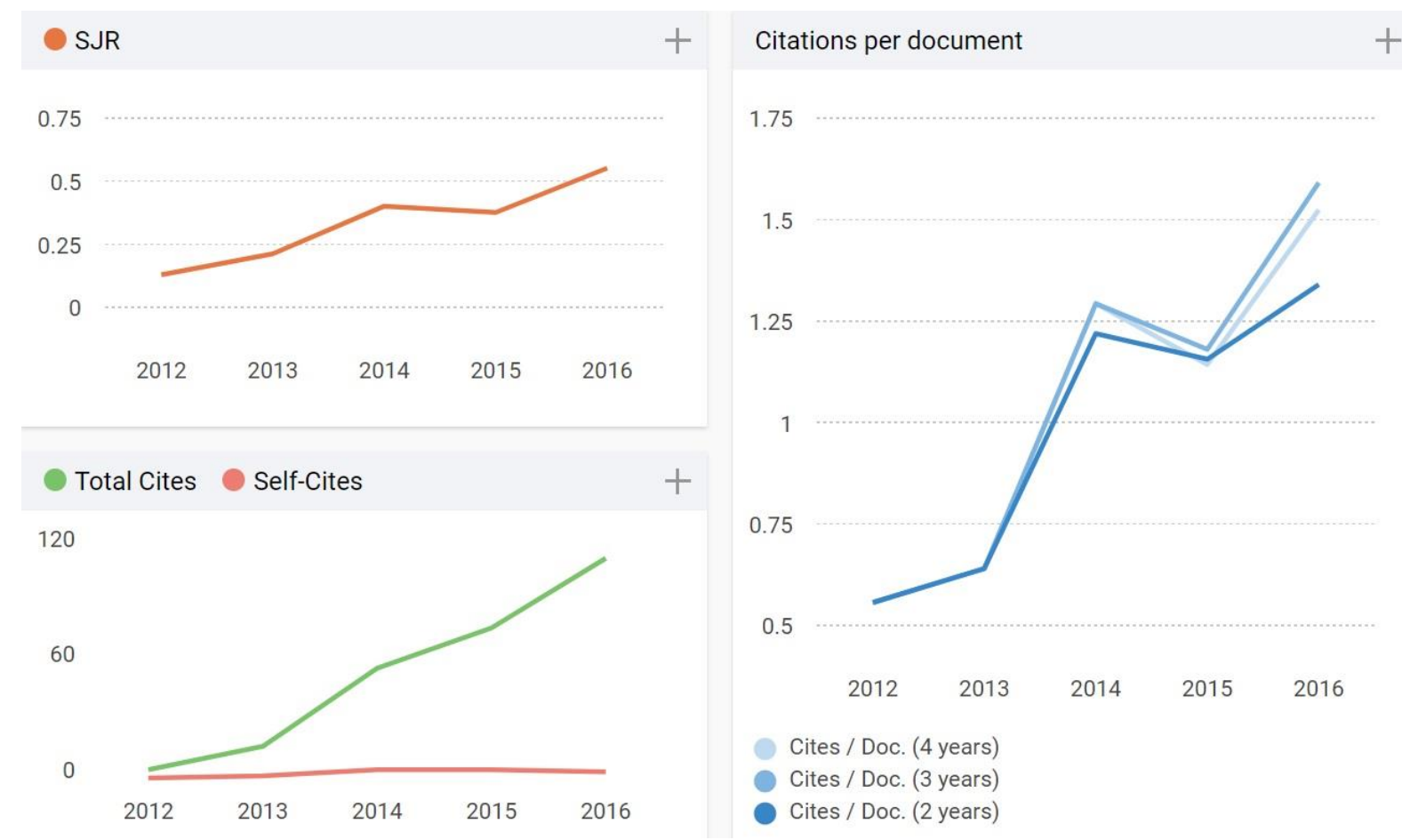

Figure 1. SCImago Journal Rank, Citations per document and total cites for Cyberpsychology. Source:

http://www.scimagojr.com

During this period, Cyberpsychology had 73,600 unique visitors with over 117,000 page views. On average, the website had 12,200 visitors per month. However, you can see that the amount of visitors is increasing over time in Figure 2. In November 2017, we had more than 16,000 visitors and we expect this increasing trend to continue.

\section{Unique visitors per week}

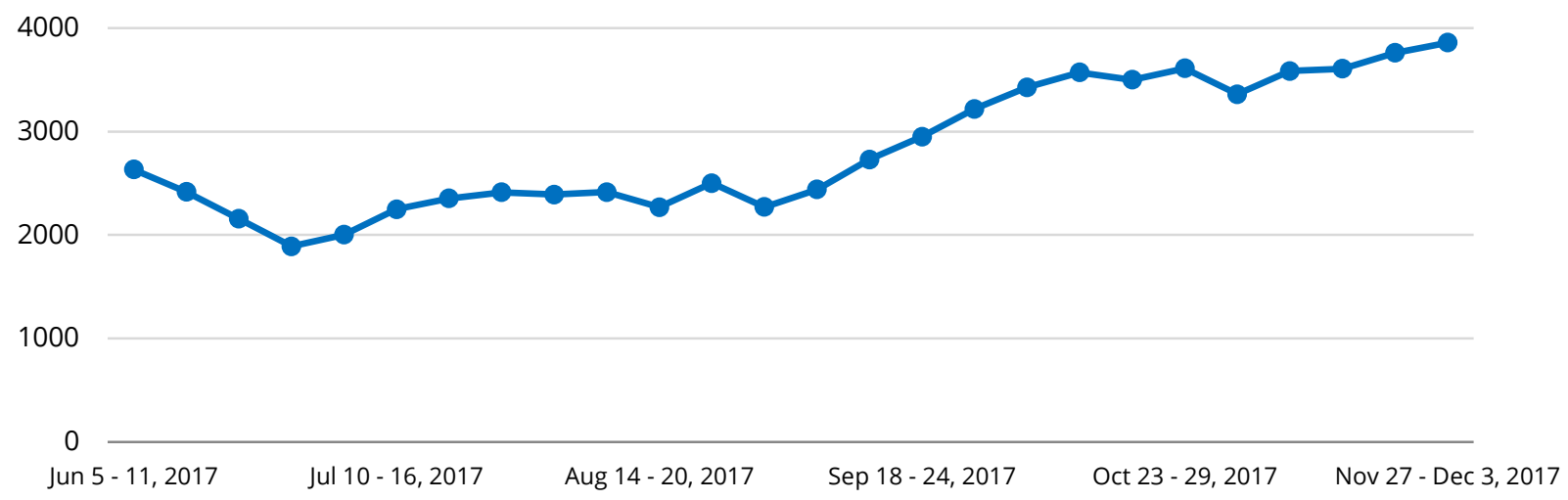

Figure 2. Unique visitors of Cyberpsychology, weekly basis, interval from June 5 to December 3, 2017.

And where do the visitors of Cyberpsychology come from? The audience is very international. Data shows that readers come from 192 countries around the world. Concerning continents, we had most visitors from North America (23k), followed by Asia (22k), Europe (19k), Oceania (4k), Africa (4k), and South and Central America (2k). Concerning countries, most visitors are from the United States (19k), followed surprisingly by the Philippines (8k), the United Kingdom (6k), Australia (3k), Canada (3k), India (3k), Malaysia (2k), Germany (2k), Indonesia (2k), the Netherlands (1k), and South Africa (1k). We are proud to see that people from around the world, with a high variability of local languages, read Cyberpsychology. 


\section{Number of Submissions and Time for Decisions in 2017}

In this section, we report only statistics from the "standard" issues which are managed by the main editors of the journal. Special issues, which are managed by guest editors, are excluded from this statistics. In 2017, we received 92 new submissions for standard issues, which is $22 \%$ more than the year before. We sent out 113 decisions, what is a $20 \%$ increase from 2016.

Of the 113 decisions, almost 50\% were desk rejects, which means that the editor rejected the article without advancing it to the external review process. The reasons for such decisions remain the same over the years - see our editorial from 2014 for a summary of the main reasons for desk rejects. To help authors improve their manuscripts prior to the submission, we also summarized the main points of why we accept manuscripts.

From the articles that are sent for external review, we rejected another half based on reviewer recommendations and encouraged revisions for the rest. From all of the decisions made in 2017, 8.8\% were accepts; this is a decrease from 2016 when we made nearly $14 \%$ accept decisions.

The average time from submission to decision remained similar as last year: three to five months if the article was externally reviewed. Desk rejects averaged two weeks. We believe these figures are helpful for authors who aim to publish in our journal. Since the first issue of this year's volume, we have added new editorial information for each published article. Hence, at the end of the article, you can find information about when the article and its revisions were submitted, and when it was accepted for publication.

Now it is time to introduce the articles in this issue.

\section{Articles in this Issue}

This issue consists of five articles by authors from various countries who used various research methods and designs.

The first article, "An experimental test of the effects of online and face-to-face feedback" (Vossen, Koutamanis, \& Walther) focuses on the effect of receiving confirming vs. disconfirming feedback for individuals' self-disclosure of their self-esteem and how these effects differ between online and face-to-face communication. This research reveals that feedback has a significant indirect effect on self-esteem through the receiver's reciprocal feedback. Interestingly, the authors found differences between online and offline communication: participants reciprocated negative feedback when they received it online more than in face-to-face communication. This reciprocal feedback enhanced the self-esteem of participants for online communication, but not in face-to-face communication.

The second article, "Exploring how social networking sites impact youth with anxiety: A qualitative study of Facebook stressors among adolescents with an anxiety disorder diagnosis" (Calancie, Ewing, Narducci, Horgan, \& Khalid-Khan) is based on a qualitative investigation which included focus groups with adolescent Facebook users who have a primary anxiety diagnosis. The young participants described how Facebook can influence their anxiety. The analysis revealed six themes related to Facebook stressors: seeking approval, fearing judgment, escalating interpersonal issues, wanting privacy, negotiating self and social identity, and connecting \& disconnecting. Participants also reported a fear of receiving negative online comments and discussed strategies for how to avoid them. Participants described feeling positive emotions when they received "likes"; however, they considered these emotions as "false", "unreal", and "fleeting." The authors conclude that there are various mechanisms through which Facebook may exacerbate anxiety in adolescents with a diagnosed anxiety disorders and thereby may make them vulnerable to negative online experiences.

The third article, "Discovering unique profiles of adolescent information and communication technology (ICT) use: Are ICT use preferences associated with identity and behaviour development?" (Kurek, Jose, \& Stuart) aims to discover the patterns for how young people use multiple types of information and communication technology (ICT) in their everyday lives and how these patterns may be associated with key aspects of their development. 
The authors surveyed 933 adolescents and used latent profile analysis. The article describes how the concepts of identity and individual behaviour are associated with individual ICT usage preferences.

The fourth article, "A preliminary study exploring moderating effects of role stressors on the relationship between Big Five personality traits and workplace cyberloafing" (Varghese \& Barber) is focused on the phenomenon of "cyberloafing", which can be described as using the internet for personal use while at work. The presented research addresses whether work stressors strengthen the relationship between personality and cyberloafing based on the Personal Resource Allocation framework. The authors carried out the online survey among employees from diverse occupations and revealed that role conflict was the only stressor that predicted cyberloafing. Role conflict strengthened the positive association between neuroticism and cyberloafing, and also the negative association between agreeableness and cyberloafing.

The fifth article, "Does 'clicking' matter? The role of online participation in adolescents' civic development" (Machackova \& Serek) describes the role of online civic participation in the development of adolescents. The study examines the longitudinal effect of online participation on the development of civic identity, political selfefficacy, and attitudes toward social authorities. The authors used data from a longitudinal two-wave panel study carried out in the Czech Republic. The research revealed that online participation predicted the increase of challenging attitudes towards social authorities, while offline participation had the opposite effect. Furthermore, offline participation positively predicted civic identity.

We hope you will enjoy reading this issue. We also thank all of the authors, reviewers, and people who contribute to the journal. We wish you a wonderful 2018 and we hope you stay in touch throughout the year and beyond.

\section{Issue Content}

\section{Editorial}

Editorial: Cyberpsychology has readers from 192 countries

David Smahel, Kristian Daneback, and Lenka Dedkova

https://dx.doi.org/10.5817/CP2017-4-xx

\section{Articles}

Article 1:

An experimental test of the effects of online and face-to-face feedback on self-esteem

Helen G. M. Vossen, Maria Koutamanis, and Joseph B. Walther

https://doi.org/10.5817/CP2017-4-1

Article 2:

Exploring how social networking sites impact youth with anxiety: A qualitative study of Facebook stressors among adolescents with an anxiety disorder diagnosis

Olivia Calancie, Lexi Ewing, Laura D. Narducci, Salinda Horgan, and Sarosh Khalid-Khan

https://dx.doi.org/10.5817/CP2017-4-2

Article 3:

Discovering unique profiles of adolescent information and communication technology (ICT) use: Are ICT use preferences associated with identity and behaviour development?

Anna Kurek, Paul E. Jose, and Jaimee Stuart

https://dx.doi.org/10.5817/CP2017-4-3 
Article 4:

A preliminary study exploring moderating effects of role stressors on the relationship between Big Five personality traits and workplace cyberloafing

Lebena Varghese, Larissa K. Barber

https://dx.doi.org/10.5817/CP2017-4-4

Article 5:

Does 'clicking' matter? The role of online participation in adolescents' civic development

Hana Machackova and Jan Šerek

https://dx.doi.org/10.5817/CP2017-4-5

\section{About the Journal}

The Cyberpsychology: Journal of Psychosocial Research on Cyberspace is a web-based, peer-reviewed scholarly journal. The first peer-reviewed issue was published in September 2007. The journal is focused on social science research about cyberspace. It brings psychosocial reflections of the impact of the Internet on people and society. The journal is interdisciplinary, publishing works written by scholars of psychology, media studies, communication science, sociology, political science, nursing, ICT security, organizational psychology and also other disciplines with relevance to psychosocial aspects of cyberspace. The journal accepts original research articles, as well as theoretical studies and research meta-analyses. Proposals for special issues are also welcomed.

The journal is indexed with Web of Science (ESCI), SCOPUS, ERIH PLUS, EBSCO Academic Search Complete, the Directory of Open Access Journals and the Czech Database of Scientific Journals.

The articles in Cyberpsychology: Journal of Psychosocial Research on Cyberspace are open access articles licensed under the terms of the Creative Commons Attribution Non-Commercial License which permits unrestricted, noncommercial use, distribution and reproduction in any medium, provided the work is properly cited.

\section{Editor}

Prof. David Smahel, M.Sc. et Ph.D., Faculty of Social Studies, Masaryk University, Czech Republic

E-mail: smahel(at)fss.muni.cz

\section{Associate Editor}

Prof. Kristian Daneback, Ph.D., University of Gothenburg, Sweden

E-mail: kristian.daneback(at)socwork.gu.se

\section{Managing Editor}

Lenka Dedkova, Ph.D., Faculty of Social Studies, Masaryk University, Czech Republic

E-mail: Idedkova(at)fss.muni.cz

\section{Editorial Board}

Prof. Kaveri Subrahmanyam, Ph.D., California State University, Los Angeles, USA

Prof. Herbert Hrachovec, Ph.D., University of Vienna, Austria

Prof. Dr. Micheline Frenette, Universite de Montreal, Canada

Prof. Alexander E. Voiskounsky, Ph.D., Lomonosov Moscow State University, Russia

Prof. Michael W. Ross, Ph.D., DrMedSc, MPH, MPHEd, University of Texas, Houston, USA

Prof. Petr Macek, CSc., Masaryk University, Czech Republic

Prof. Olle Findahl, World Internet Institute, Sweden

Prof. Jochen Peter, Ph.D., University of Amsterdam, Netherlands 
Prof. Veronika Kalmus, Ph.D., University of Tartu, Estonia

Prof. Joshua Fogel, Ph.D., Brooklyn College of the City University of New York, USA

Prof. Gustavo S. Mesch, Ph.D., University of Haifa, Israel

Prof. Lelia Green, Ph.D., Edith Cowan University, Australia

Prof. Michel Walrave, Ph.D., University of Antwerp, Belgium

Michelle Wright, Ph.D., Masaryk University, Czech Republic

Václav Štětka, Ph.D., Loughborough University, United Kingdom

Andra Siibak, Ph.D., University of Tartu, Estonia

Adjunct Prof. Birgit U. Stetina, Ph.D., University of Vienna, Austria

Anna Sevcikova, Ph.D., Masaryk University, Czech Republic

\section{Advisory Board}

Prof. Bente Traen, Ph.D., University of Oslo, Norway

Prof. Charles Ess, Ph.D., University of Oslo, Norway

Prof. Dr. Ilse Kryspin-Exner, University of Vienna, Austria

Prof. PhDr. Jan Jirák, Ph.D., Charles University, Czech Republic

Prof. Vasja Vehovar, Ph.D., University of Ljubljana, Slovenia

Prof. Larry D. Rosen, Ph.D., California State University, USA

Prof. Patricia M. Greenfield, Ph.D., University of California, USA

Prof. Peter K Smith, University of London, England

Prof. Nicola Döring, Ilmenau University of Technology, Germany

Prof. Kimberly Young, Ph.D., St. Bonaventure University, USA

Prof. Jos de Haan, Ph.D., Erasmus University, Netherlands

Prof. Zbyněk Vybíral, Ph.D, Masaryk University, Czech Republic

Prof. Monica Whitty, Ph.D., University of Leicester, UK

Prof. Alistair Duff, Ph.D., Edinburgh Napier University, Scotland

Assoc. Prof. Alfred Choi, Ph.D., Nanyang Technological University, Singapore

Prof. Thurasamy Ramayah, Universiti Sains Malaysia, Malaysia

Assoc. Prof. Neil Coulson, Ph.D., The University of Nottingham, UK

Assoc. Prof. Kenneth C. C. Yang, Ph.D., University of Texas at El Paso, USA

Assoc. Prof. Sun Sun Lim, Ph.D., National University of Singapore, Singapore

Prof. Sameer Hinduja, Ph.D., Florida Atlantic University, USA

Assoc. Prof. Jana Horáková, Ph.D., Masaryk University, Czech Republic

Assoc. Prof. Radim Polčák, Ph.D., Masaryk University, Czech Republic

Assoc. Prof. Pille Pruulmann-Vengerfeldt, Ph.D., University of Tartu, Estonia

Assist. Prof. Alexander Schouten, Ph.D., Tilburg University, Netherlands

Assist. Prof. Ewa S. Callahan, Ph.D., Quinnipiac University, USA

Assist. Prof. Regina van den Eijnden, Ph.D., Utrecht University, Netherlands

Assist. Prof. Veysel Demirer, Ph.D., Süleyman Demirel Üniversitesi, Turkey

PhDr. Ing. Petr Soukup, Charles University, Czech Republic

Janis Wolak, Ph.D., University of New Hampshire, USA

Francesca Romana Seganti, Ph.D., Sapienza University of Rome, Italy

Jeff Gavin, Ph.D., University of Bath, UK

Hana Macháčková, Ph.D., Faculty of Social Studies, Masaryk University, Czech Republic

Michael Fenichel, Ph.D., New York, USA

Leslie Haddon, Ph.D., London School of Economics, UK

\section{Publisher}

Masaryk University, Faculty of Social Studies

Jostova 10, 60200 Brno

Czech Republic 


\section{Publication Schedule}

Four issues per year: two regular issues (in July and December) plus two special issues (between regular issues)

\section{About Authors}

David Smahel, Ph.D. is the Professor at the Institute of Children, Youth and Family Research, Masaryk University, the Czech Republic. He is member of Interdisciplinary Research Team on Internet and Society (IRTIS) which researches social-psychological implications of the internet and technology. Current research focuses on adolescents' and adults' internet use, the online risks of children and adolescents, the construction of online identities and virtual relationships, and online addictive behavior. He is editor of Cyberpsychology: Journal of Psychosocial Research on Cyberspace and has co-authored book Digital Youth: The Role of Media in Development (Springer, 2011). Smahel also published in several international journals such as Developmental Psychology, Cyberpsychology \& Behavior, Zeitschrift für Psychologie, European Journal of Developmental Psychology and others. He is also author of several book chapters, such as in Encyclopedia of Cyber Behavior, Encyclopedia of Adolescence, Internet Addiction: A Handbook and Guide to Evaluation and Treatment, Gesundheit und Neue Medien etc.

Lenka Dedkova, Ph.D., is a researcher at the Institute for Research of Children, Youth and Family (Masaryk university, Brno, Czech republic) and a member of Interdisciplinary Research Team on Internet and Society (IRTIS) which researches social-psychological implications of the internet and technology. Her research interests include cyberbullying and meeting online strangers, with focus on children and adolescents, but she's also interested in online security behavior and social networking sites. Lenka also works as managing editor of Cyberpsychology: Journal of Psychosocial Research on Cyberspace.

Kristian Daneback, Ph.D. is the Professor of Social Work at the University of Gothenburg, Sweden and in the Faculty of Social Studies at Masaryk University in Brno, Czech Republic. His main field of research is sexuality and in particular internet sexuality, but he is also interested in other internet related phenomena such as parenthood and the internet, cyberbullying, and how the internet can be used to collect qualitative and quantitative data. Daneback has published his research in several well known international journals such as Archives of Sexual Behavior, Cyberpsychology, Behavior, \& Social Networking, Journal of Sexual and Relationship Therapy, Journal of Bisexuality, and Sexual Addiction \& Compulsivity. In addition, he is a reviewer for journals such as Journal of Sex Research, Journal of Computer Mediated Communication, Pediatrics, Sex Roles, and Sexual Reproduction \& Health Care. Currently he serves as the Associated Editor of Cyberpsychology: Journal of Psychosocial Research on Cyberspace and is a Board Member of the Open Journal of Communication and ISRN Family Medicine. Daneback is also a member of the International Academy of Sex Research and the Association of Internet Researchers. 